\title{
Strategic Leadership of the Business Organization and the Role of the Manager-Leader
}

\author{
Assoc. Prof. PhD Velislava Nikolaeva \\ Varna Free University “Chernorizets Hrabar”, Varna, Bulgaria \\ nikolaeva100@abv.bg
}

\begin{abstract}
In the study of the theory and practice of business management, it is more and more often commented on the new qualities that a modern leader should possess. This substantiates the author's research interest in exploring and analyzing the relationship between the leader's leadership behavior and the manager and the organization's leadership. The focus is on the knowledge, roles, and skills that a leader needs to possess that are considered to determine the leadership behavior of the organization he or she is managing in a rapidly changing environment. The purpose of the publication is to synthesize and systematize the qualities and characteristics of the leadership behavior of the manager, which are a prerequisite for achieving strategic success and leadership of the entire business organization. On this basis, to identify areas of knowledge and skills with which to upgrade the competencies of modern managers.
\end{abstract}

Keywords: strategic leadership, leader, strategic success, leader qualities, knowledge and skills.

JEL Code: M10; doi:10.36997/IJUSV-ESS/2019.8.1.118

\section{Въведение}

При изучаването на теорията и практиката на бизнес управлението все по-често се коментират новите качества, които трябва да притежава съвременният ръководител. С това се аргументира изследователския интерес на автора да изследва и анализира релацията между лидерското поведение на ръководителя и лидерството на организацията. Фокус е поставен върху знанията, ролите и уменията, които трябва да притежава лидерътръководител и които се смятат за определящи лидерското поведение на управляваната от него организация в условията на бързо променяща се среда. Целта на разработката е да се синтезират и систематизират качества и характеристики на лидерското поведение на мениджъра, които са предпоставка за постигане на стратегически успех и лидерство на цялата бизнес организация. На тази основа да се идентифицират области от знания и умения, с които да се надградят компетентностите на съвременните ръководители.

В изложението на текста се коментират въпроси, свързани със стратегическото управление и развитие, както и с поведението на ръководителя.

\section{1. Специфика на стратегическото лидерство и предпоставки за развитие на бизнес организацията}

Развитието на бизнес организацията изисква съблюдаването на редица правила при осъществяването на различни управленски процеси, които са предпоставка за устойчивото и пазарно присъствие. В този смисъл аргументирано може да се предположи, че стратегическото управление подпомага осъществяването на различни дейности и инициативи, които способстват бизнес развитието. При отчитането на промените в средата, чрез него се систематизират мерки и инициира поведение, което позволява изпълнението на дългосрочните цели, и генерирането на резултати, които подпомагат формирането на конкурентни предимства, и които водят до повишаването на конкурентоспособността на бизнес организацията. Предвид силно изразената комплексност на стратегическото управление в организацията се генерират и редица синергични ефекти, които също подлежат на планиране, управление и последващо мултиплициране.

Това извежда на преден план умението на фирменото ръководство да осъществява резултатно стратегическо управление, което не само да подпомага и гарантира постигането на формулираните цели, но и да обединява служителите в процеса на тяхното изпълнение. 
Променя се характера на поведението на мениджърите, увеличава се и се актуализира набора от знания и умения, които те трябва да притежават, за да отговорят на предизвикателствата на средата - вътрешна и външна. Именно стратегическото управление подпомага формирането на такова поведение по отношение на средата, което повишава устойчивостта на бизнес организацията при нейни негативни влияния. Предпоставка за стратегическо лидерство е ефективното стратегическо управление, което включва непрекъсната организационна трансформация в съответствие с предварително поставените цели.

Резултатите от осъществяваното стратегическо управление, а от там и на стратегическото лидерство са предпоставени и от установените рискове, които съществуват пред компанията, а именно: ${ }^{1}$

- Неумение да се анализира ситуацията и да се разработват подходящи стратегически алтернативи, адекватни на получените резултати от проведените анализи и диагностика на средата.

- Неумение да се планира и прогнозира.

- Наличието на съпротива и неумение на фирменото ръководство да се справи с нея.

- Неумение да се идентифицират „слаби сигнали“, които да се отразят в стратегическото поведение на бизнес организацията.

- Неумение да се идентифицират, осигуряват и управляват стратегическите ресурси - материални, финансови, кадрови, информационни.

- Неумение да се осъществяват стратегически промени - финансови, кадрови, технологични, структурни, процесни.

- Неумение на ръководството на организацията да се противопостави на натиска, който конкурентите оказват (стратегическа уязвимост).

- Липса на гъвкавост в мисленето и неумение да се действа ситуационно.

- Неумение да се подбират правилните хора за осъществяване на промените в хода на изпълнение на фирмената стратегия.

- Неумение да се делегират права, разпределят, споделят и носят отговорности.

Минимизирането на тези рискове зависи от следните основни фактори:

- Организационна култура. ${ }^{2}$

- Умения на мениджъра да управлява. ${ }^{3}$

- Организационни условия. ${ }^{4}$

Организационната култура започва да се формира още със създаването на организацията и еволюира в хода на нейния жизнен цикъл. Тя зависи от разбирането и отношението на всичките и служители, в това число и на фирменото рьководство. В този смисъл организационната култура също подлежи на управление и има значение при осъществяването на стратегическо управление. Тя е и един от факторите, които имат отношение при постигането на стратегическо лидерство, тъй като мотивира, подпомага интеграцията и адаптацията на служителите в организацията, предполага спазването на определени правила и норми (регулираща и ориентираща функция) и в известен степен протектира негативни влияния от външната среда заради създадените, утвърдени и споделени норми на поведение. Наборът от знания, умения и компетентности, които мениджърьт притежава са определящи ефективността на неговото управление, способстват преврьщането му в лидер и са предпоставка за постигането на лидерство от самата

\footnotetext{
${ }^{1}$ Адаптирано по: Vesnin, V. (2006) Menedzhment. Moskva: Prospekt.

2 Понятието „организационна култура” се разбира като установени и споделени ценности и правила за поведение в хода на осъществяваните служебни взаимоотношения.

${ }^{3}$ Управлението е процес на целенасочено въздействие върху дадено система.

4 Всички условия в организацията, които са предпоставка за осъществяването на планираните дейности, постигането на поставените цели и не на последно място - за стратегическо лидерство.
} 
организация.

В настоящата разработка се възприема следното разбиране за стратегическо лидерство на бизнес организацията: Постигането на такива резултати (по отношение на вътрешната и външната среда), които формират устойчиви конкурентни предимства спрямо нейните конкуренти, които и позволяват да бъде предпочитан доставчик, партньор, клиент, място за осъществяване на трудовата дейност и за кариерно развитие, организация със стабилни пазарни позиции, с ясна визия за бъдещото си пазарно развитие, с гъвкава система за управление, която води до ефективно изпълнение на поставените цели.

Постигането на стратегическо лидерство от бизнес организацията е функция на осъществяваното управление от фирменото ръководство. Това аргументира необходимостта от анализ на набора от знания, умения и компетентности, които превръщат съвременния мениджър в успешен рьководител и лидер.

\section{2. Лидерство, власт и управление в бизнес организацията}

Ролята на рьководителя в бизнес организацията непрекъснато се променя и усложнява. Установява се трайна тенденция за увеличаване на знанията и уменията на мениджърите, които далеч надвишават изискванията в установените до момента писани правила и стандарти. Това извежда на преден план необходимостта от прецизиране на отговорностите и задълженията на ръководителите в новите условия, в които те изпълняват своите функции, както и идентифициране на областите, в които е необходимо формирането на нови знания и умения.

Ръководството обичайно се свързва с властта. Способността да се влияе върху даден човек или група от хора поставя във фокуса на анализите източниците на власт и потенциала на мениджърите те успешно да бъдат използвани в тяхното ежедневие.

В специализираната литература и практика в управлението на бизнес организацията са познати различни източници на власт. Независимо от възприетата класификация, внимание според автора заслужава един от най-популярните класификационни признаци, а именно - разбирането за властта според това дали има „мениджърски“ произход, или не. В първия случай става въпрос за формалната власт, а във втория - за неформалната. Безспорно за „слабите“ ръководители е по-лесно, а по-някога и единствено възможно, да използват формалната власт, която притежават. За отъждествяването обаче на ръководството с лидерството, това далеч не е достатъчно. В този смисъл печелившото поведение на мениджъра, неизменно включва и използването на неформалната власт.

Настоящата разработка няма за цел да предложи всички аспекти на тълкуването на властта, а само да открои онези нейни специфики, които участват при формирането на лидерското поведение, което, според защитаваната теза, е в основата и на стратегическото лидерство на бизнес организацията.

В този смисъл акцент се поставя върху неформалната власт и онези източници, които формират имиджа на ръководителя отвъд формално вменените му права, задължения и отговорности. Според редица автори ${ }^{5}$ освен административната (формалната) власт, властта, която може да се използва за формиране на лидерско поведение, в т.ч., за разрешаване на различни проблеми и конфликти може да бъде:

- експертна власт;

- власт основана на информацията;

\footnotetext{
${ }^{5}$ Виж: Vesnin, V. (2006) Menedzhment. Moskva: Prospekt; Ovcharova Sn. (2019) Za nyakoi aspekti na ustoychivoto upravlenie na hora v organizatsionna sreda. Mezhdunarodno spisanie Ustoychivo razvitie, (2), pp.71-78; Bankova, V. (2019) Administrativna konfliktologiya. Varna: Universitetsko izdatelstvo VSU; Popova, D. (2019) Metamotivatsiya i kultura v razvitie. Prilozhna Psihologiya I Sotsialna Praktika XVIII Mezhdunarodna nauchna konferentsiya, 21-23 Yuni, Varna, Universitetsko izdatelstvo VSU, pp.170-182.
} 
- власт основана на доброволното подчинение - заради традиция, харизма, убеждения, споделени ценности и мотивация.

Авторьт на настоящата разработка приема твърдението, че макар и административната власт да е най-лесна за използване, конюнктурата на средата - вътрешна и външна е такава, че тя, освен че е недостатъчна за справяне с всички проблеми, пред които се изправя мениджъра, е неефективна в някои от ситуациите, с които той трябва да се справя. Нещо повече, част от спецификите на новите бизнес организации са такива, че те изискват много по-голям и разнообразен инструментариум за въздействие. Част от тези специфики са:

- Отчита се все по-малка разлика в образователното равнище на ръководителите и немалка част от служителите. Това е особено актуално във високотехнологичните сектори.

- В организации, в които заради предмета на дейност са необходими много тесни специалисти (и които обикновено се откриват и създават трудно), използването на предимно административни методи за въздействие (формална власт) върху тях е рисково и погрешно поведение.

- Глобализационните процеси, правото за свободно движение на хора, капитали и ресурси, демографските тенденции и недостига на кадри (особено в някои сектори), от една страна затрудняват подбора на кадри, от друга - провокират мениджърите да ревизират своето поведение по отношение на взаимоотношенията си с персонала, който ръководят.

- Все по-често започва да се говори за властта, която служителите имат в организацията и по-малко за тази, която ръководителите имат над тях, отчита се и увеличаване на така наречената „споделена власт“.

Изпълнявайки своите общи и специфични задължения като ръководител, мениджърите на бизнес организациите следва да се съобразяват и с влиянието на множество обективни и субективни фактори, които правят процеса на управление още по-сложен, недетерминиран, трудно поддаващ се на точно планиране, а комуникационните умения, уменията за гъвкаво и аналитично мислене, широтата на познанията на различни управленски методи, техники и подходи - задължително условие за стратегически успех както на мениджъра-лидер, така и на бизнес организацията.

Според някои автори ${ }^{6}$ образът на съвременния мениджър обобщено може да се представи като изграден от следните компоненти:

- придобити качества за упражняване на професията „мениджър“, сред които са надеждност, решителност, общителност, аналитично мислене;

- вродени качества или способности, като например - харизматичност, интелигентност, емоционална устойчивост и уравновесеност, устойчивост на стрес;

- данни свързани с биографията на ръководителя: има се предвид пол, възраст, образование, опит.

Към така систематизираните характеристики, които са определени като значими за резултатността, работата и имиджа на мениджъра може да се добави и знанието. Най-общо то е резултат от натрупан опит, включително по време на обучение и може да се представи като специфична, синтезирана и систематизирана информация, която има практическо значение за осъществяваните дейности и процеси.

Уменията, от своя страна, отразяват способността практически да се приложат акумулираните знания.

\footnotetext{
6 За повече информация виж: Kulik, I. et al. (2013) Menedzhment organizatsii. Minsk: BGU; Ovcharova, Sn. (2019) Upravlenie na kreativni hora v organizatsionna sreda. Varna: Meditsinski universitet Varna Pres; Temelkova, M. (2017) Liderstvo v biznes organizatsiite ot sektora na uslugite. Varna: Kolor print.
} 
Знанията, уменията и практическия опит могат да се представят като придобита специализирана и специфична информация, която се трансферира в действия, разпознаваеми и демонстрирани в практиката. Всички те са в основата на професионалната пригодност.

Като част от начини за генериране на знания в бизнес организацията, които могат да доведат до формирането на устойчиви конкурентни предимства и лидерство, могат да се посочат:

- организиране на обучения за собствените кадри за вертикално и хоризонтално надграждане на знанията им;

- инвестиране в иновации - собствени и придобити, които подпомагат устойчивостта на развитието, на знанието, на производителността и водят до постигането на лидерство;

- учене чрез опит, генериран и от опита на бизнес организацията до момента, включително и проучване на опита на водещите компании в бранша;

- „отглеждане“ на собствени кадри, предимно чрез привличане на млади специалисти още от учебните заведения;

- привличане на специалисти от други компании чрез по-атрактивни условия за труд и развитие.

Формирането и използването на знанията в съответствие с поставените цели на организацията изисква тяхното ефективно управление, което често се представя като част от управлението на качеството ${ }^{7}$.

Управлението на знанията може да се представи като непрекъснат процес за генериране, съхраняване и използване на знания, умения и практически компетенции, които подпомагат успешното решаване на проблеми от различно естество, на разположение са на служителите в организацията и водят до повишаване на интелектуалния потенциал на организацията в хода на изпълнението на поставените цели.

В специализираната литература широко застьпена е тезата, че ефективното управление трябва да води до самоуправление. В този смисъл под самоуправление ${ }^{8}$ следва да се разбира познаване и прилагане в практиката на рационални методи и подходи за работа, при оптимално използване на личното време.

Самоуправлението води до генерирането на следните ползи:

- Изпълнение на процеси и дейности с минимална загуба на време.

- Подобряване на производствените резултати на служителя и на организацията като цяло.

- Намаляване на стреса на работното място.

- Повишаване на мотивацията и на удовлетвореността от труда.

- По-лесно изпълнение на поставените цели.

- Генериране на синергични ефекти на различни нива в организацията.

Така посочените предимства на самоуправляващата се организация могат да се използват в подкрепа на твърдението, че ефективното управление следва да води до самоуправление.

Промените в средата изискват промени в поведението на мениджърите, които да повишават тяхната пригодност и способност ефективно да управляват организацията в съответствие с новите условия. Направеният преглед на специализираната литература, както и установените тенденции в управлението, са използвани за идентифициране и систематизиране на характеристики, които според автора на настоящия текст, ще формират образа на съвременния мениджър в съответствие с потребностите и предизвикателствата на средата.

\footnotetext{
7 За повече информация виж: Kulik, I. et al. (2013) Menedzhment organizatsii. Minsk: BGU.

${ }^{8}$ Адаптирано по: Dorofeeva, L. (2015) Osnovay teorii upravleniya. Saratov: SGU.
} 


\section{3. Компетентност и умения на мениджъра от „нов тип“}

Наборът от знания, умения и компетентности, които трябва да притежават мениджьрите от нов тип според автора на настоящата разработка са систематизирани в Таблица 1.

Таблица 1. Примерни характеристики на мениджъра от „нов тип“

\begin{tabular}{|c|c|}
\hline $\begin{array}{c}\text { Функции, роли, } \\
\text { знания, умения и } \\
\text { компетентности }\end{array}$ & Фокус области на характеристиките на мениджъра от „нов тип“ \\
\hline $\begin{array}{l}\text { Функции } \\
\text { ръководителя9 }^{\text {на }}\end{array}$ & $\begin{array}{l}\text { - административна - свързана с осъществяването на управленските } \\
\text { функции; } \\
\text { • комуникационна - свързана е с осъществявания информационен } \\
\text { обмен с вътрешната и външната среда; } \\
\text { - социална - мениджърът е отговорен за социалния климат в } \\
\text { ръководената от него организация, екип; } \\
\text { - стратегическа - свързана с целеполагането и стратегическото } \\
\text { развитие на бизнес организацията, в това число и с } \\
\text { осъществяването на иновации. }\end{array}$ \\
\hline $\begin{array}{l}\text { Роли } \\
\text { ръководителя }\end{array}$ & $\begin{array}{ll}\bullet \text { • на арбитьр, коректор и посредник; } & \bullet \text { •на лидер; } \\
\bullet \text { на балансьор, обединител и провайдер; } & \bullet \text { •на информатор; } \\
\bullet \text { • на рьководител и служител; } & \bullet \text { на слушател; } \\
\bullet \text { •на приятел; } & \bullet \text { на мотиватор; } \\
\bullet \text { на стратег; } & \bullet \text { на вдъхновител; } \\
\bullet \text { на опекун; } & \bullet \text { на учител и ментор; } \\
\bullet \text { на разпределител на ресурси; } & \bullet \text { на коуч; } \\
\bullet \text { •на изолерител; } & \bullet \text { на иноватор и дизайнер; } \\
& \bullet \text { други. }\end{array}$ \\
\hline $\begin{array}{lr}\text { Базови } \\
\text { умения } \\
\text { компетентности }\end{array}$ & $\begin{array}{l}\text { • умения, свързани с осъществяваните управленски функции - } \\
\text { теоретични и практико-приложни; } \\
\text { • знания и умения за общуване и различни комуникационни техники } \\
\text { • знания и умения за диагностициране и анализиране; } \\
\text { • знания и у умения за мотивиране, включително за насърчаване } \\
\text { развитието и самоусъвършенстването на служителите; } \\
\text { • знания и умения за управление на бизнес процеси; } \\
\text { • личен стремеж към самоусъвършенстване; } \\
\text { • усет към новото и умения да го разпознава, да насърчава неговото } \\
\text { развитие и да го прилага в практиката на организацията; } \\
\text { •склонност към риск; } \\
\text { • знания и умения за управление на времето; } \\
\text { • личностни качества за ръководител и лидер; } \\
\text { •умения да осъществява ефективна обратна връзка; } \\
\text { •умения за ситуационно управление. }\end{array}$ \\
\hline Специфични & • умения и знания за осъществяване на коучинг ${ }^{10} ;$ \\
\hline
\end{tabular}

${ }^{9}$ Адаптирано по: Vesnin, V. (2006) Menedzhment. Moskva: Prospekt.

${ }^{10}$ Коучингът се възприема като нов управленски инструмент, който има положителен ефект при разкриването на потенциала на личността-обект на коучинг, води до увеличаване на знанията и уменията на мениджъра, особено когато той е в ролята на коуч, способства за създаването на синергични ефекти на различни нива в бизнес организацията и повишава индивидуалната и съвкупната производителност. 


\begin{tabular}{|c|c|}
\hline $\begin{array}{l}\text { знания, умения и } \\
\text { компетентности }\end{array}$ & $\begin{array}{l}\text { • знания и умения за управление на таланти }{ }^{11} ; \\
\text { - знания и умения за управление на промени }{ }^{12} ; \\
\text { - знания и умения за управление на събития }{ }^{13} ; \\
\text { - знания и умения за управление на знанието } \\
\text { • знания и и умения за осъществяване на реинженеринг на бизнес } \\
\text { процеси }{ }^{15} \text {; } \\
\text { - знания и умения за управление на различията }{ }^{16} ; \\
\text { • умения за привличане на сьмишленици и последователи } \\
\text { (лидерство) }{ }^{17} \text {; } \\
\text { - демонстриране на поведение, при което положителните оценки са } \\
\text { повече от отрицателните }{ }^{18} \text {. }\end{array}$ \\
\hline
\end{tabular}

Посочените специфични знания, умения и компетентности са систематизирани по този начин, тъй като се защитава позицията, че това са новите области, в които целево трябва да се обучават съвременните мениджъри при формирането на тяхната професионална пригодност. В известен смисъл някои от предложените области се предпоставят от базовата подготовка, която получават мениджърите. От друга страна задълбочаването и разширяването на теоретичното и практико-приложното им знание се изисква от предизвикателствата и тенденциите в бизнес среда, което налага и актуализиране на набора от качества, които са включени като изискуеми в длъжностната им характеристика.

Коментирайки компетентностите и уменията на мениджърите от нов тип могат да се посочат и Петте закона на успеха ${ }^{19}$, формулирани от Бърг и Ман ${ }^{20}$ :

- Закон за автентичността.

\footnotetext{
11 Управлението на таланти се свързва със способността на мениджърите да откриват и развиват таланта потенциала на своите служители. В този смисъл може да се открие известна релация и с умението на мениджърите да използват коучинг в своята практика. Важно е да се отбележи, че управлението на талантите и прилагането на коучинг предполага използването на различен инструментариум и изисква различен набор от знания, умения и компетентности, които мениджъра трябва да притежава.

12 Управлението на промените е свързано преди всичко със създаването на подходящ организационен климат за случване на планираните промени и целево въздействие върху сьпротивата за осъществяване на планираните промени.

${ }_{13}$ В този смисъл трябва да се разбира способността на мениджъра да организира изпълнението на различни дейности и процеси.

14 Управлението на знанието предполага разработването на набор от правила, посредством които да се систематизира, стимулира и насьрчава генерирането на информация, която да подпомогне осьществяваните бизнес процеси. Управлението на знанията предполага осъзнаването на факта, че знанията не са съсредоточени само в ръководителя, Липсата на система за управление на знанията в организацията е предпоставка за появата на т. нар. „разрив на компетентностите“.

15 Способността на мениджърите за адекватно организационно преструктуриране и оптимизиране на осъществяваните процеси в бизнес организацията.

16 Фокусът е поставен върху способността на мениджъра да създава среда на толерантност и приемане на различията, среда на сьтрудничество и подкрепа при изпьлнението на целите на организацията.

${ }^{17}$ Една от все по-важните роли на мениджърите е тази на обединител - да успява лесно да привлича и мотивира служителите за активно и конструктивно участие при осъществяване на необходимите промени.

18 Установено е, че когато положителните оценки (поощренията) са повече от отрицателните (критиката), мотивацията на служителите и тяхната производителност се увеличава. Това поведение кореспондира с т. нар. „Ефект на Пигмалион”, който ще се коментира по-назад в изложението.

${ }^{19}$ Според автора на разработката, макар и тези закони да са адресирани конкретно към печелившото пазарно поведение, те ясно заявяват необходимостта от демонстрирането на определено поведение, което подпомага изпълнението на поставените цели. Това дава основание да се твърди, че формулираните от Бърг и Ман „закони на успеха“" имат отношение и приложение при анализиране на лидерското поведение на мениджъра, като предпоставка за лидерство на бизнес организацията.

${ }^{20}$ Barg, B., Dzh. Man. (2011) Day, za da poluchish. Malka istoriya za golyamata biznes tayna. Sofiya: Kragozor.
} 
- Закон за приемането.

- Закон за влиянието.

- Закон за стойността.

- Закон за възнаграждението.

Според Закона за автентичността поведението трябва да е такова, че да внушава доверие. По този начин се печелят съмишленици и последователи, изгражда се доверие, проправя се път към по-ефективното постигане на поставените цели. Постулатите на този Закон могат да се използват като естествена препратка към Закона за влиянието. Според него силата на влиянието върху околните, зависи от способността да се поставят техните интереси пред собствените и да се демонстрира поведение на емпатия. Демонстрирането на съпричастност може да се отнесе към качествата, които са печеливши при изграждането на имиджа на ръководителя. Те подпомагат процесите по формиране и управление на екипи, улесняват осъществяването на промени и намаляват съпротивата, която може да възникване в организацията, в хода на осъществяване на връзките на субординация.

Законът за приемането също се смята за подходящ и приложим от онези ръководители, които искат да бъдат успешни, да се превърнат в лидери и да ръководят по начин, който да превърне организацията в лидер. Застъпва се тезата, че „ефективното даване“ е пряко свързано с умението да се получава - новите идеи и подкрепата са също толкова важни за успеха, колкото и удовлетворението, че с демонстрираното поведение е постигната някаква полезност и другаде.

Според Закона за стойността трябва да се постига усещането, че се получава повече, отколкото се дава. В сравнителен план стойността предполага ранжиране - нещо е постойностно от друго. По подобен начин може да се интерпретира и Закона за възнаграждението - за колкото повече хора създаваш стойност и полезност, демонстрирайки приемане и влияние, толкова повече съмишленици ще има мениджъра. В този смисъл „възнаграждението“ не се приема като материален приход, а като хора, колективи и аудитории към които е демонстрирано печелившо поведение и от които се очаква същото поведение.

В случаите, в които се коментират характеристиките на мениджърите от „нов тип“ се установява необходимост към набора от знания, умения и компетентности да се добавят и такива, свързани с психологията и техниките за комуникация. Начинът на мислене на мениджърите, демонстрирането на този начин пред подчинените има влияние върху техните резултати. Изследванията в тази посока са безспорни. В контекста на разглежданата проблематика, според автора, внимание заслужават следните три ефекта: ефект на Пигмалион ефект на Галатея и Хало ефект ${ }^{21}$.

В Таблица 2 са систематизирани ключови особености на посочените по-горе ефекти.

Таблица 2. Психологически ефекти в помощ на мениджъра от нов тип

\begin{tabular}{|l|c|}
\hline \multicolumn{1}{|c|}{ Ефект } & Характеристика на ефекта \\
\hline Ефект на & $\bullet$ Познат е още като ефект на Розентал и Джейкъбсън. \\
Пигмалион & $\bullet$ Ефектът показва влиянието на положителните очаквания на мениджърите \\
& по отношение на работата и резултатите на ръководените от тях хора. \\
& $\bullet$ Демонстрирайки своите положителни очаквания, мениджърът съзнателно \\
& или не транспонира тези свои очаквания върху своите служители. \\
& Служителите, осъзнато или не, заради заявяваните високи очаквания от \\
& мениджърите, постигат по-добри резултати от обичайното. \\
\hline
\end{tabular}

21 За повече информация виж: Korsini, R. (1998) Psihologiya: entsiklopediya. Sofiya: Nauka i izkustvo. 


\section{IZVESTIA JOURNAL OF THE UNION OF SCIENTISTS - VARNA}

\begin{tabular}{|c|c|}
\hline & $\begin{array}{l}\text { • Зависимостта „заявявани очаквания на мениджърите-резултати на } \\
\text { подчинените“ е права }{ }^{22} \text {. }\end{array}$ \\
\hline $\begin{array}{l}\text { Ефект на } \\
\text { Галатея }\end{array}$ & $\begin{array}{l}\text { - Поставя фокус върху очакванията на личността за собствената си } \\
\text { резултатност }{ }^{23} \text { В този смисъл може да се проявява и при мениджъри, и } \\
\text { при служители. } \\
\text { • Положителните/ отрицателните очаквания за постигнати лични резултати } \\
\text { от мениджъра/ служителя към самия себе си, водят до постигане на по- } \\
\text { добри/ по-лоши резултати. (Ефект на Галатея/ ефект на Голем). } \\
\text { • Положителната нагласа относно собствените възможности повишава } \\
\text { самочувствието и убедеността в личния потенциал за справяне дори с } \\
\text { много сложни задачи. }\end{array}$ \\
\hline $\begin{array}{l}\text { Хало } \\
\text { ефект }\end{array}$ & $\begin{array}{l}\text { - Хало ефектът е известен още като ефект на ореола. } \\
\text { • Изразява се в субективно влияние на една или няколко възприети } \\
\text { характеристики на дадена личност върху преценката за нея. Тази } \\
\text { характеристика може да е положителна или отрицателна. Положителната } \\
\text { промяна в оценката се нарича Хало ефект, а отрицателната - Ефект на } \\
\text { дявола. } \\
\text { •Проявата на ефекта е свързана с наличието на някои от следните } \\
\text { обстоятелства: оскъдна или неактуална информационна осигуреност, } \\
\text { ограниченост при възприемането или тълкуването на информацията и др. } \\
\text {-Хало ефектът води до преекспониране на реалната оценка на личността. }\end{array}$ \\
\hline
\end{tabular}

Умението на мениджърите да осъществяват промени се влияе от редица фактори и предпоставки. Като по-значими от тях могат да се посочат:

- Способността на ръководителя да диагностицира правилно средата и да определя необходимостта от промени.

- Способността да се подбере екип от съмишленици, с които да се осьществи промяната.

- Умения за целеполагане, включително по отношение на необходимата промяна.

- Умения за комуникация и за създаване на информационна система за осъществяване на промяната.

- Умение да се рискува и да се осъществява промяната от страна на самия мениджър с виждане как това да се случи.

- Ясно осъзнаване на обстоятелството, че положителните ефекти от промяната няма да дойдат веднага.

Усилията на мениджъра от „нов тип“ следва да бъдат насочени към създаването на такъв организационен климат, който да води до появата на т. нар. „самообучаваща се организация“.

Терминът „самообучаваща се организация“ е въведен от Питър Сенги ${ }^{24}$. Според него това е организация, която генерира, съхранява, разпространява и мултиплицира знания. Правейки това, тя придобива способността да се променя, развива и постига своите цели, които, на базата на ефективното управление на знанията и осигуряват устойчивост, конкурентоспособност и лидерство.

\footnotetext{
22 Когато очакванията са положителни и резултати също, се приема, че действа ефекта на Пигмалион. При демонстрирани отрицателни очаквания и получени незадоволителни резултати, се приема, че действа ефекта на Голем.

${ }^{23}$ Efektat na Galateya ili taynata na triumfa. [Online] Available from: https://bg.psychologyinstructor.com/efektt-nagalateya-ili-taynata-na-triu/ [Accessed 27/09/2019]

24 За повече информация виж: Sengi, P. (2012) Petata distsiplina. Sofiya: Iztok-Zapad
} 
Петте елемента, които Сенги нарича „технологии“ или „дисциплини“ са:

1. Системно мислене. Основава се на разбирането, че мисленето трябва да е комплексно. То трябва да обхваща всички елементи и процеси в системата бизнес организация и да я анализира както и от позицията, че тя самата е суперсистема, така и че е подсистема.

2. Лично майсторство. Влага се разбирането, че хората трябва да се стремят и постигат съвършенство по отношение на процесите и дейностите, които извършват в бизнес организацията. Това е постижимо ако служителите, в това число и мениджъра, непрекъснато се стремят да се обучават и развиват. Това следва да бъде подпомагано и от целенасочената политика на бизнес организацията.

3. Ментални модели. Тази „дисциплина“ се свързва със способността да се избират правилни модели за поведение, обучение, вземане на решения. Фокусът е не само самопознанието, но и насърчаването на поведение, което да води до повишаване степента на самопознание на служителя, екипите, организацията.

4. Изграждане на споделена визия. Според Сенги условие за организационния успех на самообучаващата се организация са споделените ценности, правила, норми, цели и виждания за бъдещето на бизнес организацията.

5. Екипно учене. Основава се на синергичните ефекти, които се получават от „споделеното“ мислене. Чрез „диалог“ знанието се мултиплицира, генерират се повече идеи, постигат се по-добри резултати.

При самообучаващата се организация служителите, независимо от тяхната длъжност и талант са в основата на нейната производителност и просперитет, гъвкавостта в поведението и мисленето се приема за стратегическо предимство, а управлението на промените е предпоставка за стратегически успех. В среда на самообучаваща се организация, служителите със своите усилия, начин на мислене, поведение, желание за учене и обучение непрекъснато увеличават способността си да получават резултатите, които са заявени и желани.

Според американския психолог Майк Педлер ${ }^{25}$ могат да се посочат следните характеристики на самообучаващата се организация:

- разработването на стратегията и тактиката на организацията е с активното участие на служителите;

- добрата отчетност и контрол, подпомагат организационното развитие;

- акумулираната информация се използва за анализиране и изучаване на случващото ce, в подкрепа на правилно взетите решения, а не за определяне на възнаграждение или наказание;

- използване на гъвкав подход при формирането и осъществяването на стратегията и непрекъснато насърчаване на процеса на учене за тяхното подобряване;

- насърчаване на комуникацията и вътрешния обмен на информация и услуги между структурните звена;

- създаване на възможности за развитие и саморазвитие на служителите;

- изграждане, поддържане и развиване на атмосферата и политика в организацията, която насърчава ученето и самообучението;

- използване на гъвкави система за възнаграждение на служителите;

- подходяща комуникация и обмен на опит с различни контактни аудитории;

- анализ и диагностика на средата, резултатите от които да са достьпни за всички служители.

Така идентифицираните специфики на самообучаващата се организация могат да се използват за аргументиране на ролите, знанията, уменията и компетентностите, които

\footnotetext{
25 За повече информация виж: Ivanova, E. (2014) Upravlenie izmeneniyami. Moskva: MGUPS (MIIT).
} 
ръководителите трябва да притежават, за да бъдат успешни. Използвайки систематизираните примерни характеристики на мениджърите от нов тип (таблица 1), аргументирано може да се предположи, че в основата на ефективното стратегическо управление като предпоставка за стратегическо лидерство е осъществяването на такова поведение, че организацията да се превърне в самообучаваща се, а управлението да прераства в самоуправление.

\section{Заключение}

Стратегическото лидерство на бизнес организацията е резултат от усилията и възможностите на фирменото ръководство. С това се аргументира необходимостта от непрекъснато надграждане на знанията, уменията и компетентностите на мениджърите, които носят отговорност за развитие на фирмата и за изпълнението на поставените цели. Систематизираните в изложението функции и роли, които ръководителите изпълняват в своето ежедневие, могат да се използват за идентифициране на областите от знания, които участват при формирането на тяхната професионална пригодност и които способстват за преврьщането им в лидери. Установява се необходимост от задълбочаването на т. нар. „меки умения", от развитие на инструментариума за вземане на решения и надграждане на уменията за управление на хора и екипи, както и за генериране и внедряване на иновации в различни области, дейности и процеси в бизнес организацията, които да подпомогнат нейното устойчиво развитие и постигането на лидерски позиции.

\section{References}

1. Bankova, V. (2019) Administrativna konfliktologiya. Varna: Universitetsko izdatelstvo VSU.

2. Barg, B., Dzh. Man. (2011) Day, za da poluchish. Malka istoriya za golyamata biznes tayna. Sofiya: Kragozor.

3. Vesnin, V. (2006) Menedzhment. Moskva: Prospekt.

4. Dorofeeva, L. (2015) Osnovay teorii upravleniya. Saratov: SGU.

5. Efektat na Galateya ili taynata na triumfa. [Online] Available from: https://bg.psychologyinstructor.com/efektt-na-galateya-ili-taynata-na-triu/ [Accessed 27/09/2019]

6. Ivanova, E. (2014) Upravlenie izmeneniyami. Moskva: MGUPS (MIIT).

7. Korsini, R. (1998) Psihologiya: entsiklopediya. Sofiya: Nauka i izkustvo.

8. Kulik, I. et al. (2013) Menedzhment organizatsii. Minsk: BGU.

9. Ovcharova, Sn. (2019) Upravlenie na kreativni hora v organizatsionna sreda. Varna: Meditsinski universitet Varna Pres.

10. Ovcharova Sn. (2019) Za nyakoi aspekti na ustoychivoto upravlenie na hora v organizatsionna sreda. Mezhdunarodno spisanie Ustoychivo razvitie, (2), pp.71-78.

11. Temelkova, M. (2017) Liderstvo v biznes organizatsiite ot sektora na uslugite. Varna: Kolor print.

12. Popova, D. (2019) Metamotivatsiya i kultura v razvitie. Prilozhna Psihologiya I Sotsialna Praktika XVIII Mezhdunarodna nauchna konferentsiya, 21-23 Yuni, Varna, Universitetsko izdatelstvo VSU, pp.170-182.

13. Sengi, P. (2012) Petata distsiplina. Sofiya: Iztok-Zapad. 